\title{
Energy recovery and nutrients recycling from municipal sewage sludge
}

\author{
Probir Das ${ }^{\mathrm{a}, *}$, Shoyeb Khan ${ }^{\mathrm{a}}$, Mohammed AbdulQuadir ${ }^{\mathrm{a}}$, Mahmoud Thaher ${ }^{\mathrm{a}}$, Muhammad Waqas ${ }^{\mathrm{a}}$, \\ Ahmed Easa ${ }^{\text {b }}$, Essam Shabaan Mohamed Attia ${ }^{b}$, Hareb Al-Jabri ${ }^{\text {a }}$ \\ a Algal Technology Program, Center for Sustainable Development, College of Arts and Sciences, Qatar University, Doha, 2713, Qatar \\ ${ }^{\mathrm{b}}$ Central Laboratory Unit, College of Arts and Sciences, Qatar University, Doha, 2713, Qatar
}

\section{H I G H L I G H T S}

- Optimal HTL conditions could recover $58 \%$ energy of the MSS with a EROI value of 3.5 .

- Increasing HTL reaction time reduced the TOC and increased TN in APL.

- Metals concentrations in the biochar get reduced compared to raw MSS.

- TP in the biochar increased with increase in HTL reaction time.

- Microalgal recycling efficiency of the nutrients from the APL was strain dependent.

\section{G R A P H I C A L A B S T R A C T}

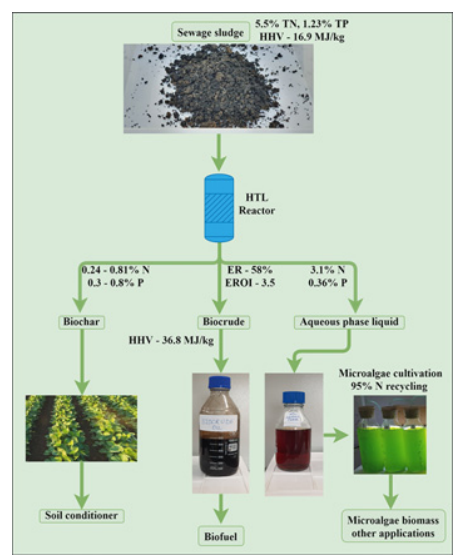

\begin{abstract}
A B S T R A C T
Hydrothermal Liquefaction (HTL) could be a promising and better alternative to other techniques for energy recovery from municipal sewage sludge (MSS). However, the nutrients (i.e., $\mathrm{N}$, and $\mathrm{P}$ ) recovery potential from the byproducts, generated in the HTL of MSS, needs to be studied so that a comprehensive sludge management practice could be adopted. In this study, HTL process temperature $\left(275-400{ }^{\circ} \mathrm{C}\right)$, and reaction time $(30-120 \mathrm{~min})$ were first investigated for biocrude yield and release of the nutrients to the aqueous phase liquid (APL) and biochar. The maximum energy recovery (i.e., 59\%) and maximum energy return on investment (i.e., 3.5) were obtained at $350{ }^{\circ} \mathrm{C}$ and $60 \mathrm{~min}$ of holding time. With the increase in HTL reaction time, the concentration of nitrogen in the APL increased ( 5.1 to $6.8 \mathrm{mg} / \mathrm{L}$ ) while the concentration of phosphorus decreased ( 0.89 to $0.22 \mathrm{mg} / \mathrm{L}$ ); the opposite was observed for the biochar. The nutrient recycling efficiency from the APL using microalgae was found to be strain-specific; nitrogen recycling efficiency by Picochlorum sp. and Chlorella sp. were 95.4 and $58.6 \%$, respectively. The APL, derived from $1 \mathrm{~kg}$ MSS, could potentially produce $0.49 \mathrm{~kg}$ microalgal biomass. Since the concentrations of various metals in the biochar samples were substantially lower compared to their concentrations in raw MSS, the application of biochar as a soil conditioner could be very promising. Overall, net positive energy could be recovered from MSS using the HTL process, while the nutrients in the APL could be used to cultivate specific microalgae, and biochar could be applied to enhance the soil quality.

(c) 2020 Elsevier B.V. All rights reserved.
\end{abstract}

\footnotetext{
* Corresponding author.

E-mail address: probir.das@qu.edu.qa (P. Das).
} 


\section{Introduction}

The treatment of various industrial and municipal wastewater is often achieved using a combination of physicochemical and biological treatment processes. During the biological treatment process, a group of bacteria degrades the soluble and colloidal organic matters while increasing the cell numbers; this process generates bacterial biomass, which is later separated together with other inorganic and organic compounds from the treated water as biosludge (Korzeniewska and Harnisz, 2018). A significant portion of this biomass, together with other organic and inorganic pollutants, are separated (as sludge) from the water before the water is treated or polished further prior to discharge. Per capita average biosludge generation was reported in the range of 34.5-125.5 g DM/day (Werle and Sobek, 2019). In Qatar, 23 wastewater treatment plants (WWTP) produce 40,000 tons of sludge per year (Alsheyab and Kusch-Brandt, 2018; Water Statistics In the State of Qatar, 2017).

Organic content in the biosludge would typically be around $50-80 \%$, which would mainly depend on the wastewater characteristics and operating conditions in the treatment plant (Prestigiacomo et al., 2019). If municipal wastewater mixed with industrial wastewater, the generated biosludge is often found to have heavy metals, pathogens, toxic chemicals (Maag et al., 2018). Hence, proper treatment of the municipal sewage sludge (MSS) would be required before disposal or land application as a biofertilizer. In the absence of any use of this biosludge, landfilling remains one of the most common ways of biosludge management (Chanaka Udayanga et al., 2019). However, landfilling of biosludge is often linked with the release of greenhouse gases (GHGs), and toxic gases, and leachate that could potentially contaminate the soil and groundwater (Kleemann et al., 2017; Lim et al., 2018; Mu et al., 2019). Also, the biosludge is usually dried and transported to a designated area for landfilling - all these processes increase the cost and energy burden of the wastewater treatment (Avelar et al., 2019). The cost of biosludge disposal could vary from place to place (Wang et al., 2017; Zhao et al., 2019), and it alone could contribute to the 50\% cost of the wastewater treatment facilities (Tomei et al., 2016; Yang et al., 2019). On the contrary, because of the intrinsic calorific value of the biosludge, energy recovery, as biogas or bio-oil, could simultaneously reduce the volume of sludge and contribute to offsetting the cost and energy balance of the sludge management (Kaur et al., 2019; Qian et al., 2020). While some technologies (e.g., pyrolysis, incineration, and co-firing with coal) would require a dry biosludge, some other technologies, like anaerobic digestion (AD), and hydrothermal liquefaction (HTL), could process the wet biosludge (Castello et al., 2018). In some cases, methane is generated by the anaerobic digestion of the sludge which later can be used to generate electricity (Xu and Dai, 2020). Similar to the AD process, drying of wet sludge is not necessary for HTL conversion of MSS into biocrude; instead, the water associated with the sludge can be used for maintaining the temperature and pressure in the HTL (Lu et al., 2018; Suárez-Iglesias et al., 2017). While the AD process relies on the microbes, HTL would use heat and pressure to process the MSS; therefore, faster and higher recovery of energy from the MSS could be possible in the HTL process.

Apart from biocrude, other byproducts (biochar, aqueous, and gas phase compounds) would be formed in the HTL process (Han et al., 2019). Aqueous phase liquid (APL) would contain dissolved, and potentially toxic, organic compounds and nutrients (i.e., nitrogen, phosphorus, and other elements) of the MSS. The presence of nitrogen and phosphorus in the biocrude is not desirable, rather if these are partitioned from raw MSS to the byproducts of the HTL process, it could offer improved nutrients recycling opportunity. While earlier studies on HTL of MSS mainly focused on the biocrude yield and quality, it would be, therefore, necessary to study how HTL process parameters could optimize the partitioning of these nutrients into the byproducts.

Use of hydrothermal gasification (Watson et al., 2017), and anaerobic digestion (Torri and Fabbri, 2014; Wang et al., 2019) of the APL could directly recover a fraction of the available energy in the APL. However, nitrogen, phosphorus, and other metals will remain in the APL after these processes - requiring additional techniques for treating the processed APL or recovering the nutrients. The energy recovery potential from the APL would be low because of the low concentration of dissolved organic in it (Leng et al., 2018). The addition of APL in microalgal growth media could not only treat the APL, but also allow the recycling of $\mathrm{N}, \mathrm{P}$, and other trace metals in a single process; this could enhance the environmental sustainability of the sludge management and promote a circular economy. Although microalgae were used to recover the nutrients from the microalgae biomass-derived APL (Das et al., 2019b, 2020), there is a need to study the feasibility of growing microalgae using MSSderived APL. For comprehensive management of MSS, detailed characterization of biochar would be required so that an appropriate application of biochar could be proposed.

HTL operating conditions (i.e., temperature, and duration) could not only affect the biocrude yield but also the distribution of nutrients in different HTL products. Therefore, the first objective of this study was to develop HTL operating conditions which could optimize both the biocrude yield and nutrients release from MSS. Since a number of microalgal strains were able to uptake nutrients from different toxic wastewaters it could be possible that microalgal strains would also be able to recycle nutrients from the APL derived from the HTL of MSS. Therefore, the second objective of this study was to determine the nutrient recycling efficiency from the APL by two microalgae strains.

\section{Materials and methods}

\subsection{Collection and storage of the sludge}

$4 \mathrm{~kg}$ wet sludge was collected from a municipal wastewater treatment plant, Doha, in a plastic container. Upon bringing the sample to the lab, the wet sludge was further dewatered using a cloth filter. Next, the sample was further concentrated using a benchtop centrifuge. The centrifuged sample was placed inside a plastic container and kept inside $\mathrm{a}-20^{\circ} \mathrm{C}$ fridge.

\subsection{Estimation of moisture content in municipal sewage sludge}

$1 \mathrm{~g}$ of wet sewage sludge was kept in an oven at $105^{\circ} \mathrm{C}$ overnight; the sample was removed from the oven weighed again, and moisture content was calculated using Eq. (1).

$$
\begin{aligned}
& \text { Moisture content }(\%) \\
& \quad=\{(\text { Initial weight }- \text { final weight }) / \text { Initial weight }\} * 100
\end{aligned}
$$

\subsection{Estimation of ash content in municipal sewage sludge}

The sample, used for moisture content determination, was taken for ash content analysis. A known quantity of dry municipal sewage sludge was placed in a ceramic crucible and kept in a muffle furnace at $540{ }^{\circ} \mathrm{C}$ for a period of $4 \mathrm{~h}$. Ash content was determined using Eq. (2).

$$
\begin{aligned}
\text { Ash content }(\%)= & \{(\text { Initial weight }- \text { Final wieght }) / \text { Initial weight }\} \\
& * 100
\end{aligned}
$$

\subsection{Elemental analysis of dry municipal sewage sludge sample}

C, $\mathrm{H}$, and $\mathrm{N}$ values of the dry MSS were calculated using a Flash 2000 CHN analyzer (ThermoFisher Scientific, USA); oxygen was calculated based on the difference. $S$ content in the samples was determined separately. Initially, the samples were digested in $100 \mathrm{~mL}$ mini highpressure bomb reactors using concentrated HNO3; the concentration of sulfur in the digested samples was later determined by an Agilent 
7700 series inductively coupled plasma - optical emission spectrometry (ICP-OES) machine. The concentrations of various metals in the digested sample were also determined using the ICP-OES machine.

\subsection{Determining the higher heating value for dry municipal sewage sludge}

Based on values obtained from elemental analysis, higher heating value (HHV) of various liquid and solid samples was calculated using the Dulong formula:

Higher Heating value $(\mathrm{MJkg})=0.338 \mathrm{C}+1.428(\mathrm{H}-08)+0.095 \mathrm{~S}$

\subsection{Procedure for making biocrude oil from municipal sewage sludge using} hydrothermal liquefaction process

Swagelok high-pressure fitting (SS-1210-6; 0.75) with a working volume of $10 \mathrm{~mL}$ was used for conducting HTL of the MSS. Each HTL experiments were conducted in triplicates. $1 \mathrm{~g}$ of dry MSS and $7 \mathrm{~mL}$ of deionized water were added in a Swagelok Union, and the opening was closed using a plug. All the reactors were kept in a preheated furnace, set at predetermined time and temperature. Initially, the HTL experiments were conducted at a temperature range of $275-400{ }^{\circ} \mathrm{C}$ and 30 min of holding time. Next, the HTL experiments were conducted for a holding time range of 30-120 min, at optimum temperature. After the completion of the HTL reaction, the reactors were removed from the furnace and cooled down immediately to room temperature. The plug from the reactor was opened for the gases to vent out. Next, $10 \mathrm{~mL}$ dichloromethane (DCM) was added in the reaction mixture to facilitate the formation of two separate phases: the upper phase was the aqueous phase, and the bottom layer was the organic phase. Both the phases were separated, centrifuged, and then analyzed for the yields of biocrude and biochar, and characterization of the aqueous phase.

\subsection{Determination of biocrude and biochar yield}

A known amount of organic layer (i.e., $2 \mathrm{~mL}$ ) was collected in a glass tube and placed at $60{ }^{\circ} \mathrm{C}$ in a HACH DRB 200 block heater for 10 min to evaporate DCM. After DCM was vaporized, the biocrude sample was weighed, and the corresponding yield was calculated. For determining the biochar yield, the centrifuged pellets from aqueous and organic phases were collected and kept in an oven at $105^{\circ} \mathrm{C}$ overnight; dried char was weighed, and biochar yield was determined.

2.8. Determining energy recovery and energy return on investment from the sewage sludge

Energy recovery (ER\%) and energy return on investment (EROI) were calculated by the following equations, as described by Liu et al. (2018) and Yoo et al. (2015).

$($ ER $\%)=$ Biocrude yield $(\%) \times \operatorname{HHV}($ biocrude $) / \mathrm{HHV}($ feedstock $)$

$($ EROI $)=$ Energy $($ output $) /$ Energy $($ input $)$

where Energy (output) $=$ HHV (biocrude) $\times$ biocrude yield

Energy $($ input $)=\mathrm{Q}_{\mathrm{f}}+\mathrm{Qw}$

where $Q_{f}$ is heat energy for heating $1 \mathrm{~g}$ of MSS

Qw is heat energy for heating $7 \mathrm{~g}$ water

2.9. Characterization of the various products of the HTL process

\subsubsection{Biocrude}

Various organics in the biocrude samples were identified using 7890A Agilent Technologies Gas Chromatography (GC) system coupled with a 5973 network MS detector. The details of the sample preparation and GC-MS operating conditions were provided previously (Das et al., 2019a). Biocrude oil sample was digested using concentrated nitric acid in a mini high-pressure bomb reactor at $140{ }^{\circ} \mathrm{C}$ for $4 \mathrm{~h}$; the concentration of sulfur in the digested sample was determined using ICP-OES.

\subsubsection{Aqueous phase liquid}

The concentrations of total organic carbon (TOC), total nitrogen (TN), and total phosphorus (TP) in APL were determined using LCK385, LCK138, and LCK349 HACH kits, respectively.

\subsubsection{Biochar}

Energy dispersive X-ray (EDX) was used to identify the presence of the various metals in the biochar samples and the MSS. The biochar samples were digested by $\mathrm{HNO}_{3}$ and the concentration of various metals in the digested liquid samples were determined by ICP-OES machine. $\mathrm{C}, \mathrm{H}$, and $\mathrm{N}$ elements in the biochar samples were determined using the Flash 2000 CHNS analyzer.

\subsection{Growth study of microalgae using the aqueous phase nutrients}

One freshwater Chlorella sp., and another marine Picochlorum sp. were selected for studying the recycling potential of aqueous phase nutrients (see Supplementary). $50 \mathrm{~mL}$ culture of each strain was mixed with $950 \mathrm{~mL}$ of water (desalinated water for Chlorella sp., and seawater for Picochlorum sp.) in $1 \mathrm{~L}$ size glass photobioreactor (PBR). In control sets, for both strains, $78 \mathrm{mg} / \mathrm{L}$ urea $\left(36.4 \mathrm{mg} / \mathrm{L} \mathrm{N}\right.$ ) and $10 \mathrm{mg} / \mathrm{L} \mathrm{KH}_{2} \mathrm{PO}_{4}$ were added as nitrogen and phosphorus sources; for the experimental set, a specific amount of aqueous phase liquid was added to match half of the nitrogen concentration of the control set. The trace metals were added as Guillard f/2 medium. For the experimental cultures, all the nutrients were added as half of the control culture. The cultures inside the PBRs were agitated using compressed air at a rate of $0.5 \mathrm{~L} / \mathrm{m}$. These growth studies were conducted inside a temperature control room $\left(25 \pm 1{ }^{\circ} \mathrm{C}\right)$ using white fluorescent lighting $\left(600 \mu \mathrm{mol} \mathrm{E} / \mathrm{m}^{2} / \mathrm{s}\right)$. The growth of these strains was monitored daily using the spectrometric reading at $750 \mathrm{~nm}$ using a $\mathrm{HACH} 3900$ spectrophotometer. The calibration curves of these two strains, for biomass density vs. optical density at $750 \mathrm{~nm}$, were previously established. The concentrations of TN, TP, and TOC in the experimental growth media, at the end of the experiment, were also determined. All the experiments were conducted in triplicates.

\subsection{Statistical analysis}

All the experiment was conducted in triplicates. The values reported here are the average of three independent samples. Standard error was used to represent error bars in the graphs. One - Way ANOVA ( $\alpha=$ 0.05 ) was used to determine the significance difference among the means of independent treatments.

\section{Results and discussion}

\subsection{Characteristics of the municipal sewage sludge}

The moisture content of the collected sewage sludge was $83.59 \%$. The ash content in dried MSS was 39.5\%. Typical ash content in MSS was reported in the range of 35-40\% (Leng et al., 2014; Malins et al., 2015). The concentrations of $\mathrm{C}, \mathrm{H}$, and $\mathrm{N}$ in the dried MSS were 30.5 , 6.15 , and $5.5 \%$, respectively. The HHV of the sewage sludge was calculated as $16.9 \mathrm{MJ} / \mathrm{kg}$. The typical energy content value of dried MSS was reported in the range of 16.1-21.3 MJ/kg (Liu et al., 2018; Xu et al., 2018). Phosphorus content in the MSS was reported in the range of 15.3-26.2 g/kg (Bridle and Pritchard, 2004; Qian and Jiang, 2014); the collected MSS had a phosphorus content of $12 \mathrm{~g} / \mathrm{kg}$. The concentrations of metals in the collected MSS were compared with other MSS sources 
for details (see Supplementary); major metal elements, as identified by ICP-OES, were calcium, iron, magnesium, aluminum, potassium, and zinc.

\subsection{Effect of HTL operating conditions on the products}

\subsubsection{Operating temperature}

For a fixed duration of 30 min HTL run, six different operating temperatures were studied (Fig. 1a). The results revealed that heat played a major role in the contents of product distribution. The biocrude yield was the lowest at $275^{\circ} \mathrm{C}$, and with an increase in temperature, the biocrude yield continued to increase until $350{ }^{\circ} \mathrm{C}$, and then it started to decline till $400{ }^{\circ} \mathrm{C}$; a similar trend was observed by Leng et al. (2014). At $350{ }^{\circ} \mathrm{C}$, the maximum biocrude yield was $44.8 \%$ (ash-free dry weight basis). However, slightly higher biocrude yields 47.79 and 47.45\% from MSS samples were reported by Malins et al. (2015), and Wang et al. (2018), respectively, at lower HTL operating temperature; it should be noted that the HTL trials, in these studies, were conducted in the presence of homogeneous catalysts (i.e., $5 \% \mathrm{FeSO}_{4}, 10 \% \mathrm{CuSO}_{4}$,). Although a lower HTL reaction temperature would be advantageous, it would pose challenges in the downstream processing of product recovery and nutrient recycling. The biochar content was the highest at $275{ }^{\circ} \mathrm{C}$, and its content continued to reduce to a minimum value at $400{ }^{\circ} \mathrm{C}$; this could be due to dominance of liquefaction and hydrothermal gasification (HTG) reactions occurring at higher temperatures, thereby reducing biochar yields (Jain et al., 2016). For the reactions conducted at $375^{\circ} \mathrm{C}$ or above, supercritical conditions promoted hydrothermal gasification (HTG) reactions that could increase gaseous compounds while reducing biocrude and biochar fractions (Peterson et al.,
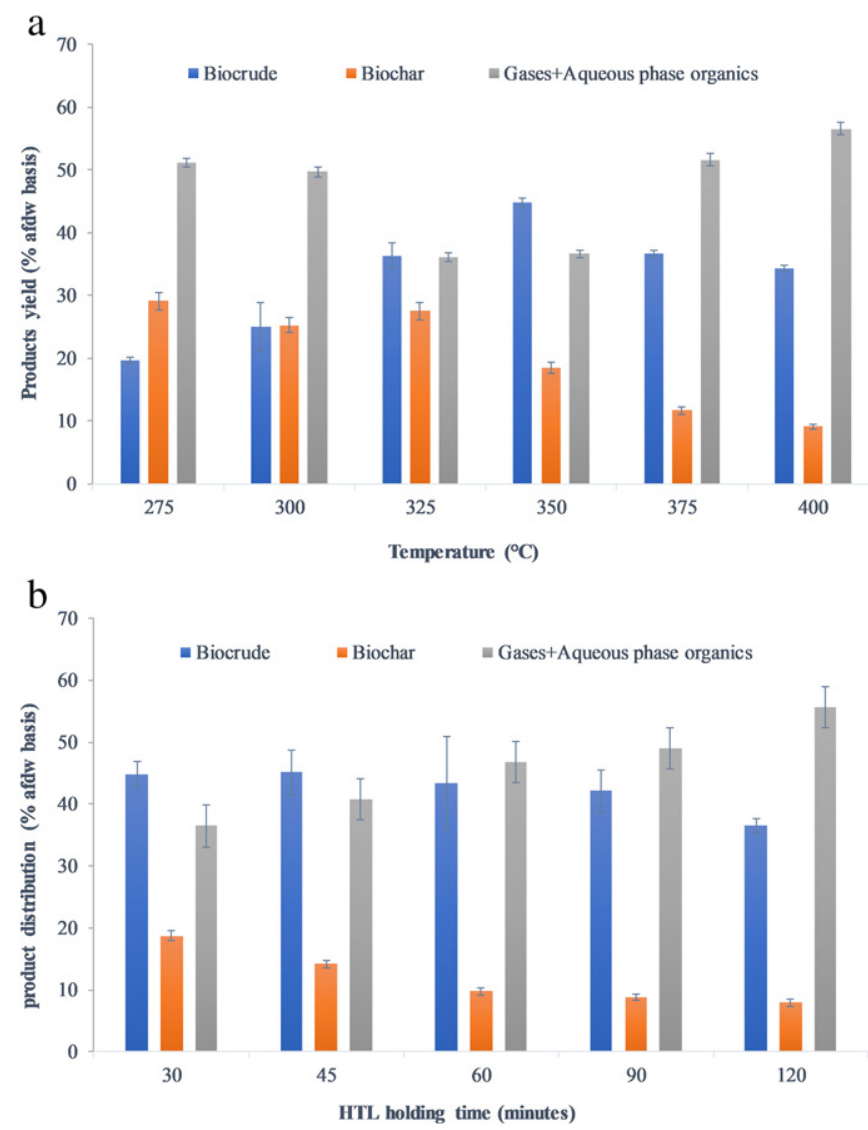

Fig. 1. (a) The distribution of various products obtained from hydrothermal liquefaction of municipal sewage sludge at different temperatures (error bar represents standard error, where $n=3$ ). (b) The distribution of various products obtained from hydrothermal liquefaction of municipal sewage sludge at $350{ }^{\circ} \mathrm{C}$ and different holding time (error bar represents standard error, where $\mathrm{n}=3$ ).
2008). Apart from biocrude and the biochar, the remaining fraction of the HTL products were available either in aqueous or in the gaseous phase, the partitioning of MSS into aqueous phase liquid and gaseous phase was in the range of $36.1-56.6 \%$. During the HTL process, a fraction of MSS-bound inorganic content could get solubilized in the aqueous phase; the aqueous phase salinity was in the range of 1.4-3.0\% due to the release of various inorganic salts in the APL. Since the maximum liquefaction of organic compounds present in sewage sludge occurred at $350{ }^{\circ} \mathrm{C}$, further optimization of HTL process (i.e., holding time) was conducted at $350{ }^{\circ} \mathrm{C}$.

\subsubsection{HTL holding time}

3.2.2.1. Distribution of products. After determining the optimum HTL operating temperature, optimum time duration was determined for the HTL process of MSS. The HTL reaction was then carried out for 30, 45, 60,90 , and $120 \mathrm{~min}$ while maintaining the temperature at $350{ }^{\circ} \mathrm{C}$; the product distribution of this study was shown in Fig. $1 \mathrm{~b}$. There was a trend of increasing biocrude yield as the time duration increased from $30 \mathrm{~min}$ up to $60 \mathrm{~min}$, and maintaining the reaction for an additional time resulted in a decrease in biocrude yield. It was possible that due to additional time, a fraction of biocrude was converted and ended up in the aqueous and gaseous phases. The highest biochar was found when the HTL reaction duration was lowest (i.e., $30 \mathrm{~min}$ ); on the contrary, the lowest biochar content was found for the maximum HTL reaction time (i.e., $120 \mathrm{~min}$ ). With increasing HTL time, more of the organic fraction of the MSS was converted into biocrude, aqueous and gaseous phases. Biocrude yields for 30 and 45 min of holding time were almost similar; however, any further increase in holding time, the biocrude yield tended to reduce. Reduced liquefaction at higher holding time could be due to the formation of gaseous phase products (Valdez et al., 2014). Biochar yields also declined with increasing reaction time; the lowest biochar yield was $7.94 \%$ at 120 min holding time. Gaseous phase products were found to increase with increasing reaction time; maximum gas formation, together with the loss, was accounted for $55.56 \%$ at $120 \mathrm{~min}$ holding time. Therefore, longer reaction time could have promoted gasification type reactions, thereby reducing both biocrude and biochar yields.

3.2.2.2. HHV of the biocrude. The elemental $(\mathrm{C}, \mathrm{H}, \mathrm{N}, \mathrm{O})$ analyses of the biocrude samples and their corresponding high heating values (HHV) were shown in Table 1. Carbon content in the biocrude samples remained almost similar for different holding times; however, hydrogen content increased, and nitrogen and oxygen content decreased with increasing HTL holding time. HHV for biocrude samples was found to increase with increasing reaction time. The biocrude sample, obtained at $90 \mathrm{~min}$ of holding time, had the maximum HHV of $36.8 \mathrm{MJ} / \mathrm{kg}$. HHV value for the HTL of MSS samples, in previous studies, was reported in the range of 27.7-36.2 MJ/kg (Malins et al., 2015; Prestigiacomo et al., 2019). Slightly higher HHV obtained in this study compared to these earlier studies could be due to higher elemental carbon and lower combined $\mathrm{N}$ and $\mathrm{O}$ content in the biocrude, obtained at longer HTL holding time. In comparison, bio-oil obtained by pyrolysis of MSS could have HHV in the range of $15.5-25 \mathrm{MJ} / \mathrm{kg}$ (Trinh et al., 2013).

3.2.2.3. Distribution of hydrocarbons in biocrude oil obtained from HTL of MSS. The GC-MS chromatographs of the biocrude samples (see Supplementary). Various organic compounds in the biocrude sample were classified into three main groups: alkanes, alkenes, and polyaromatic, and other hydrocarbons (Fig. 2). At $350{ }^{\circ} \mathrm{C}$ and all the holding times, aromatic and heterofunctional compounds together constitute bulk of the biocrude samples. On the contrary, the combined fraction of alkane and alkene compounds were in the range of $25-35 \%$ (based on the area of GC-MS chromatograph). The majority of alkanes were pentane and nonane at $30 \mathrm{~min}$, whereas at higher reaction time higher amounts cycloalkanes were formed. Hexadecene, heptadecane, and octadecene 
Table 1

Ultimate analysis of biocrude from municipal sewage sludge (MSS) at different holding time.

\begin{tabular}{llllll}
\hline & $\mathrm{C}$ & $\mathrm{H}$ & $\mathrm{N}$ & $\mathrm{O}^{\Phi}$ & $\mathrm{HHV}(\mathrm{MJ} / \mathrm{kg})$ \\
\hline $30 \mathrm{~min}$ & $72.4 \pm 0.1$ & $7.6 \pm 0.0^{\mathrm{a}}$ & $6.2 \pm 0.1^{\mathrm{a}}$ & $13.8 \pm 0.2^{\mathrm{a}}$ & $32.9 \pm 0.1$ \\
$45 \mathrm{~min}$ & $73.2 \pm 0.2$ & $8.0 \pm 0.0^{\mathrm{b}}$ & $5.1 \pm 0.0^{\mathrm{b}}$ & $13.7 \pm 0.2^{\mathrm{a}}$ & $33.8 \pm 0.1$ \\
$60 \mathrm{~min}$ & $73.4 \pm 1.6$ & $9.0 \pm 0.2^{\mathrm{c}}$ & $5.8 \pm 0.3^{\mathrm{a}, \mathrm{c}}$ & $11.8 \pm 1.7^{\mathrm{a}, \mathrm{b}}$ & $35.6 \pm 0.6$ \\
$90 \mathrm{~min}$ & $74.7 \pm 0.4$ & $9.3 \pm 0.1^{\mathrm{c}}$ & $5.9 \pm 0.2^{\mathrm{a}, \mathrm{c}}$ & $10.1 \pm 0.3^{\mathrm{b}}$ & $36.8 \pm 0.4$ \\
$120 \mathrm{~min}$ & $73.6 \pm 2.0$ & $9.3 \pm 0.2^{\mathrm{c}}$ & $5.8 \pm 0.1^{\mathrm{c}}$ & $11.3 \pm 1.8^{\mathrm{b}}$ & $36.2 \pm 0.9$ \\
\hline
\end{tabular}

All the values shown in the table are mean of three independent replicates $(n=3)$. $^{\mathrm{a}, \mathrm{b}, \mathrm{c}}$ values within a column with different superscripts are significantly different $(\mathrm{P}<0.05$; one-way ANOVA).

$\Phi$ By difference.

were major types of alkenes formed at 45, 60, and 90 min, respectively. Alkene compounds were higher compared to alkane compounds at 45 and 60 min holding time; in other holding times, a small percentage of alkene was detected. Similarly, in a previous study, Wang et al. (2018) detected alkanes, esters, and amides but no alkene in the biocrude sample - obtained from MSS at $270{ }^{\circ} \mathrm{C}$ and $30 \mathrm{~min}$ holding time in the presence of $\mathrm{CuSO}_{4}$ catalyst. Similar to HTL of MSS, pyrolysis of MSS produced more aromatics and other heteroatoms containing compounds compared to alkane, alkene, and alkynes (Gao et al., 2017; Park et al., 2010).

\subsection{Effect of HTL operating conditions on the characteristics of the aqueous phase liquid}

\subsubsection{Operating temperature}

At low reaction temperature, a lesser degree liquefaction could have contributed to higher quantities of water-soluble organic compounds. However, at higher reaction temperatures, organic compounds in aqueous phase declined; this could be due to the higher conversion of compounds not only to biocrude fraction but also to carbon dioxide or other gaseous phase products. At elevated temperature $\left(>375^{\circ} \mathrm{C}\right)$, due to the hydrothermal gasification (HTG) process, the formation of inorganic and organic gaseous compounds could occur and thereby reducing the availability of total carbon content in other products (Peterson et al., 2008). Therefore, TOC value decreased with an increase in the HTL reaction temperature (see Supplementary). Xu et al., 2018 found a similar trend for TOC value in the APL. TN values in the APL increased from $250{ }^{\circ} \mathrm{C}$ to $350{ }^{\circ} \mathrm{C}$, and then there was a decreasing trend for TN values in the APL; the recovery of TN from MSS to APL was in the range of $37.9-48.0 \%$.

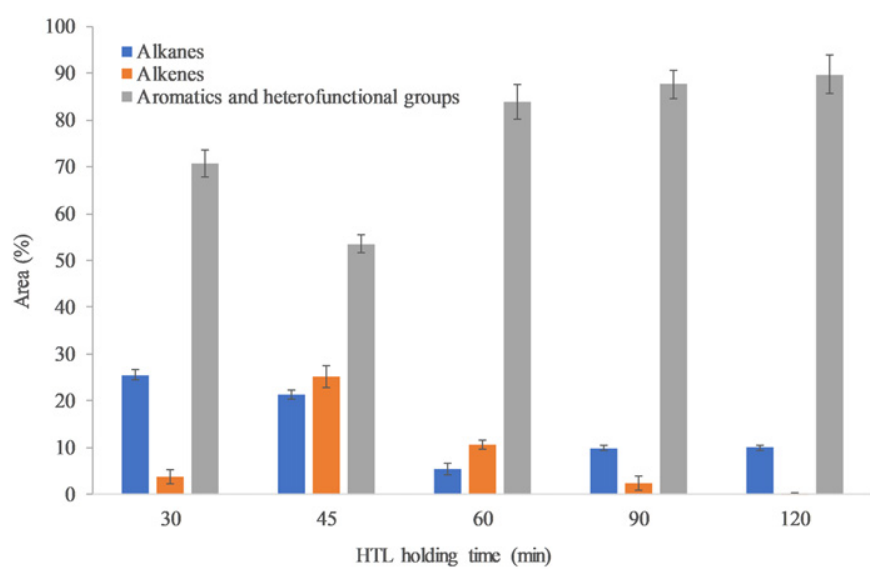

Fig. 2. Distribution of organic compounds in the biocrude samples obtained for different hydrothermal liquefaction holding time (error bar represents standard error, where $\mathrm{n}=3$ ).

\subsubsection{HTL holding time}

In this study, $15 \%$ was the solid loading, whereas the remaining fraction was water for all the HTL trials; different solid loading could simultaneously affect both the product distribution and concentration of TOC, $\mathrm{TN}$, TP, and other metals in the APL. TOC value in the aqueous phase varied from $12.75-8.3 \mathrm{~g} / \mathrm{L}$ for the holding time $30-120 \mathrm{~min}$ (Fig. 3); the higher the holding time, the lower was TOC content in the APL. On the contrary, as the HTL holding time increased, the concentration of TN in the APL increased (Fig. 3). As high as $64 \%$ of $\mathrm{N}$ of the MSS could end up in the APL for 120 min of HTL holding time. The recovery of TP from the MSS to the APL was in the range of 12.0-48.6\%; the concentration of TP in the APL reduced with an increase in HTL holding time (Fig. 3). The availability of TN and TP in the liquid digestate, after the $\mathrm{AD}$ process, could be in the range of $0.14-3.4 \mathrm{~g} / \mathrm{L}$ and $0.007-0.38 \mathrm{~g} / \mathrm{L}$, respectively (Xia and Murphy, 2016); hence, optimal HTL conditions could result in much higher release of nutrients (i.e., TN, and TP) in the APL compared to liquid digestate of the AD process.

\subsection{Distribution of major elements of MSS in HTL product and byproducts}

The distribution of 2 major elements (i.e., C, and N) from MSS to various HTL products, at $350{ }^{\circ} \mathrm{C}$ and different holding times, was determined (see Supplementary). The bulk of the $\mathrm{C}$ content was associated with biocrude for all the holding times. Small fractions of $\mathrm{C}$ content were also associated with the biochar and APL; C content in the biochar and APL reduced with increasing holding time. On the contrary, more of the $C$ content could have been converted to gaseous content with increasing holding time. Under all conditions, the highest fraction of nitrogen was present in the APL, followed by biocrude, biochar, and gas phase. As the holding time increased, the nitrogen content reduced in the biocrude, and biochar while it increased in the APL. At $350{ }^{\circ} \mathrm{C}$ temperature, $45 \mathrm{~min}$ of holding time was optimal for both biocrude yield and $\mathrm{N}$ recovery from the MSS to the APL.

\subsection{Energy recovery potential from the MSS}

The energy return on investment (EROI) and energy recovery (ER) for the HTL of MSS at $350{ }^{\circ} \mathrm{C}$ for different holding time were shown in Fig. 4; both the maximum EROI and ER values were obtained for $60 \mathrm{~min}$ of holding time. After $60 \mathrm{~min}$ of holding time, both the biocrude yield and caloric value of the biocrude were higher than those values obtained for other holding times. The EROI values were calculated based on the calorific value of the biocrude alone. For holding time $>60 \mathrm{~min}$, there could have the formation of more gaseous products, which could have reduced the EROI and ER values. On the other hand, for holding time lesser than $60 \mathrm{~min}$, more of the organic fraction could remain in the APL and biochar - reducing the EROI and ER values.

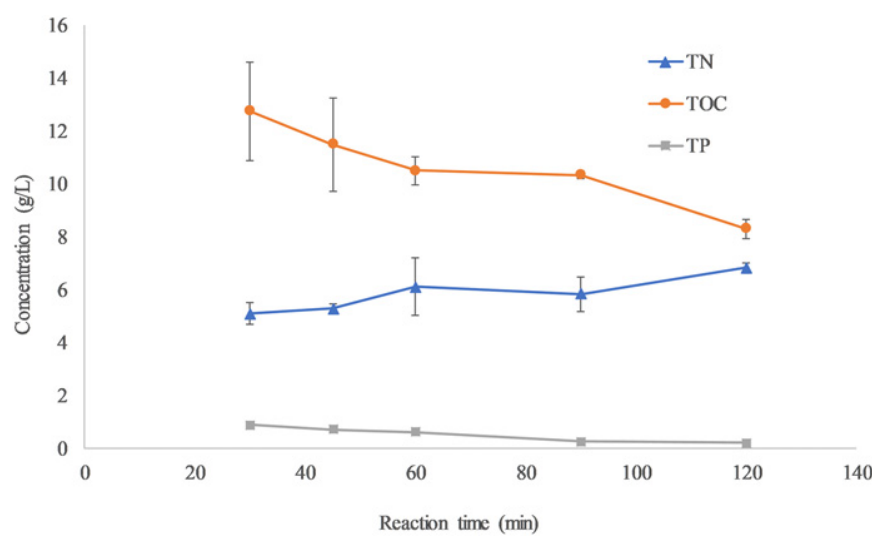

Fig. 3. Concentration of total organic carbon (TOC), total nitrogen (TN), and total phosphorus (TP) in the aqueous phase liquid (APL) obtained at $350{ }^{\circ} \mathrm{C}$ and different holding time (error bar represents standard error, where $n=3$ ). 
The energy recovery from MSS, as methane, using anaerobic digestion was calculated as 15.8\% (Gray and Donald, 2008). Energy recovery from dried MSS using the pyrolysis technique was reported as $45-48 \%$ (Bridle and Pritchard, 2004; Karaca et al., 2018). For HTL of MSS, a wide range of energy recovery (22-69.8\%) values were reported which were mainly affected by HTL operating conditions (i.e., temperature, holding time, and water content) and application of catalysts (Liu et al., 2018; Malins et al., 2015; Qian et al., 2017). Malins et al. (2015) found that the addition of a $\mathrm{FeSO}_{4}$ catalysts (5 wt\% of MSS) in the HTL of MSS (at $300{ }^{\circ} \mathrm{C}$, and 40 min holding time) could enhance the energy recovery from $53 \%$ to $69.8 \%$; catalysts were also found to improve the calorific value of the biocrude oil which could improve the EROI value of the HTL process. However, in this study, the maximum energy recovery from MSS was 57.75\%; although no catalyst was used, the optimum reaction temperature $\left(350{ }^{\circ} \mathrm{C}\right.$ ) and holding time (60 min) were higher than the conditions used by Malins et al. (2015).

\subsection{Nutrient recycling potential}

\subsubsection{Aqueous phase}

The cultures of Picochlorum sp., and Chlorella sp. in control and experimental conditions, on the 10th day (see Supplementary). The growth curves of Picochlorum sp., and Chlorella sp., in control and experimental cultures, are shown in Fig. 5 respectively. The applicability of microalgal-based nutrients recycling from the liquid digestate of the AD process was explored by Xia and Murphy (2016); the efficiency of nutrient recycling was mainly dependent on the microalgal strains. In this study, the biomass yield of Picochlorum sp. in aqueous phase supplemented culture was higher than that of the control culture. In a recent study, it was shown that Picochlorum sp. could efficiently utilize the nutrients in the aqueous phase-derived from the HTL of its biomass (Das et al., 2019b). Although the concentrations of nitrogen in both these cultures were the same, the aqueous phase liquid had dissolved organics; therefore, Picochlorum sp. could have utilized these organics in a mixotrophic mode and had higher biomass yield in the experimental culture compared to control culture. On the contrary, the biomass yield of Chlorella sp. in the control culture was higher compared to the experimental culture. The organic compounds in the aqueous phase could be toxic to the Chlorella sp. A reduction of TN in the growth media could be explained by the consumption of microalgae for metabolism and growth, and abiotic factors such as ammonia stripping and nitrification by the nitrifying bacteria (Delgadillo-Mirquez et al., 2016; López-Pacheco et al., 2019a). While a reduction of $95.4 \%$ TN was observed in the Picochlorum sp. experimental culture, it was only $58.6 \%$ in the experimental culture of Chlorella sp.; such a difference in the TN reduction could have been mainly attributed to the difference in biomass yield. Although P content in the experimental growth media was

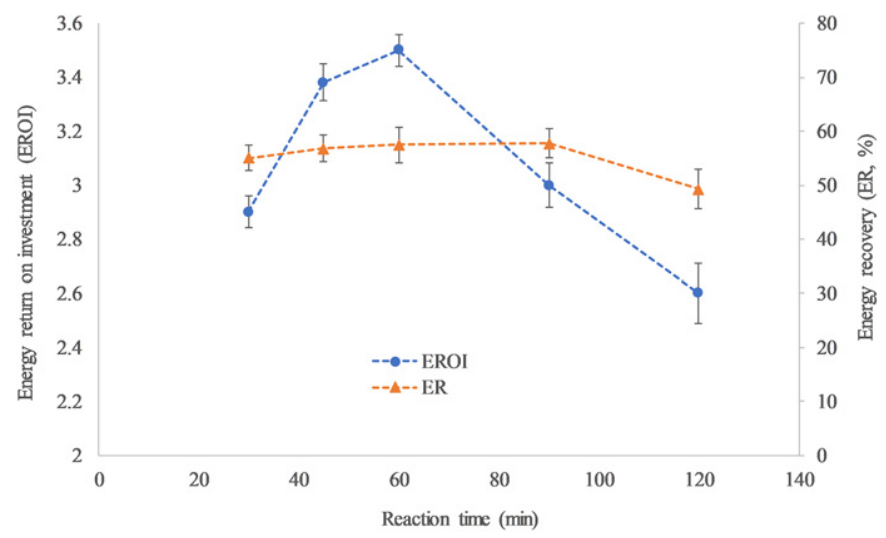

Fig. 4. Energy recovery on investment (EROI) and energy recovery (ER) values of biocrude production from municipal sewage sludge by hydrothermal liquefaction at $350{ }^{\circ} \mathrm{C}$ and different holding time (error bar represents standard error, where $\mathrm{n}=3$ ).

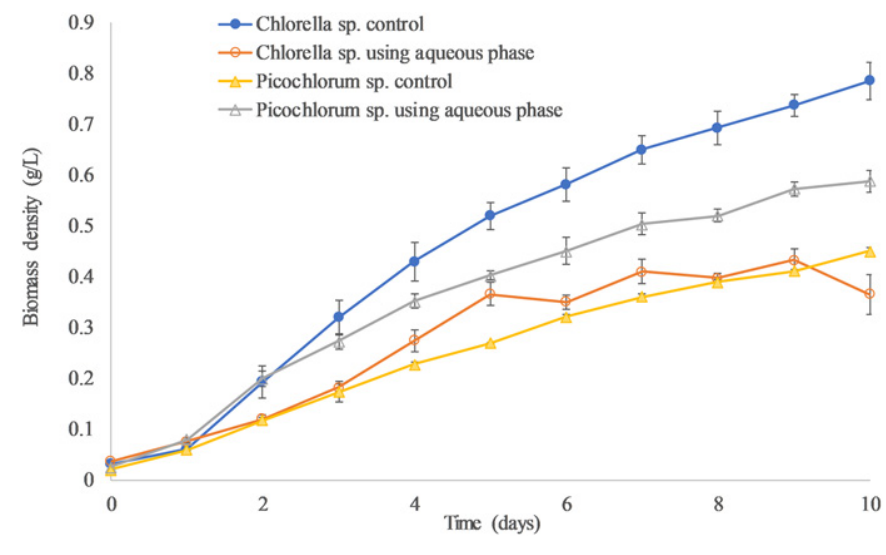

Fig. 5. Growth comparison of Chlorella sp. and Picochlorum sp. in control and aqueous phase added cultures (error bar represents standard error, where $\mathrm{n}=3$ ).

higher than the value used in the control growth media, the residual $\mathrm{P}$ content in both experimental cultures was lesser than $0.2 \mathrm{mg} / \mathrm{L}$, which could be attributed by the precipitation of insoluble phosphorus at higher $\mathrm{pH}$ values. Since no $\mathrm{CO}_{2}$ was provided during the cultivation process, the $\mathrm{pH}$ values for all the cultures increased to above 9.5 after 10 days. Similarly, earlier reports suggested that the recycling of nitrogen and phosphorus from the wastewater would depend on the characteristics of the microalga used (Delgadillo-Mirquez et al., 2016; LópezPacheco et al., 2019a). The initial TOC value in both the experimental cultures was $30 \mathrm{mg} / \mathrm{L}$; after 10 days of growth, the TOC values in the experimental Picochlorum sp. and Chlorella sp. were 1.7, and $8.0 \mathrm{mg} / \mathrm{L}$ respectively. Both the strains could have consumed a fraction of the dissolved organics in the mixotrophic mode; in addition, aeration in these cultures could have accelerated the degradation of the organics - thereby reducing the TOC values (López-Pacheco et al., 2019a). However, the untreated organic, partially treated organic, and microalgal release of exopolysaccharides (EPS) could have contributed to the residual TOC (Loftus and Johnson, 2019).

Since the cultures were not maintained in complete axenic conditions, it was possible that there could have been bacterial contamination. It was earlier reported that microalgae and bacteria together, in a symbiotic relationship, could degrade complex organic compounds, including toxic substances (Das et al., 2018a; Muñoz and Guieysse, 2006). However, since the APL was diluted 200 times in the growth media, and it had low TOC content, the potential of bacterial growth and biomass yield in the culture was minor. Regular microscopic observation of samples from the cultures of both strains revealed that none of these cultures were contaminated with other microalgae; however, especially, at the later phase of the growth study, the presence of low concentrations of bacteria (unidentified) was observed in both cultures. Nevertheless, APL could contribute at least half of the $0.59 \mathrm{~g} / \mathrm{L}$ total biomass yield for Picochlorum sp. Under optimized HTL operating conditions, $68 \%$ of the MSS bound nitrogen was released to the aqueous phase, and hence nutrients form 1 ton (dry basis) of collected MSS alone could potentially support 0.49 -ton microalgal biomass production. Although the toxic wastewater could be treated using microalgae, the produced biomass could have some estrogenic effect and hence should not be used for human and animal consumption (Correa-Reyes et al., 2007; López-Pacheco et al., 2019b). Nonetheless, the produced microalgal biomass, by using APL nutrients, could be used as biofuel feedstock (Das et al., 2019b), biofertilizer (Das et al., 2018b), and feedstock for many other renewable chemicals (Foley et al., 2011).

\subsubsection{Biochar}

Biochar was formed as a residue after the hydrothermal liquefaction process. In this study, as the holding time of HTL increased, the biochar quantity was reduced (Fig. 1b). The biochar obtained after the HTL process of MSS still had a high amount of organic content (see 
Table 2

Distribution of various elements in the biochar samples-obtained at $350{ }^{\circ} \mathrm{C}$ and different holding time.

\begin{tabular}{|c|c|c|c|c|c|c|}
\hline Elements (g/kg) & $30 \mathrm{~min}$ & $45 \mathrm{~min}$ & $60 \mathrm{~min}$ & $90 \mathrm{~min}$ & $120 \mathrm{~min}$ & Sewage sludge (this study) \\
\hline $\mathrm{Mg}$ & $3.5 \pm 0.11^{\mathrm{a}}$ & $4.1 \pm 0.14^{\mathrm{b}}$ & $5.2 \pm 018^{c}$ & $6.6 \pm 0.23^{\mathrm{d}}$ & $7.1 \pm 0.24^{\mathrm{e}}$ & $9.6 \pm 0.33^{f}$ \\
\hline $\mathrm{Al}$ & $3.53 \pm 0.12^{\mathrm{a}}$ & $3.8 \pm 0.13^{\mathrm{a}}$ & $9.2 \pm 0.32^{\mathrm{b}}$ & $8.1 \pm 0.28^{c}$ & $5.9 \pm 0.20^{d}$ & $11.1 \pm 0.38^{\mathrm{f}}$ \\
\hline $\mathrm{Si}$ & $5.3 \pm 0.18^{\mathrm{a}}$ & $6.4 \pm 0.22^{\mathrm{b}}$ & $14.3 \pm 0.50^{c}$ & $12.6 \pm 0.44^{\mathrm{d}}$ & $9.6 \pm 0.33^{\mathrm{e}}$ & $25.6 \pm 0.89^{\mathrm{f}}$ \\
\hline$P$ & $3.3 \pm 0.11^{\mathrm{a}}$ & $3.9 \pm 0.13^{b}$ & $4.1 \pm 0.14^{\mathrm{b}}$ & $4.9 \pm 0.17^{c}$ & $8.9 \pm 0.31^{d}$ & $12.3 \pm 0.43^{\mathrm{e}}$ \\
\hline $\mathrm{Ca}$ & $5.9 \pm 0.20^{\mathrm{a}}$ & $7.7 \pm 0.26^{\mathrm{b}}$ & $17.3 \pm 0.60^{\mathrm{c}}$ & $16.2 \pm 0.56^{\mathrm{c}}$ & $16.4 \pm 0.57^{c}$ & $21.1 \pm 0.73^{d}$ \\
\hline $\mathrm{Fe}$ & $2.1 \pm 0.07^{\mathrm{a}}$ & $2.9 \pm 0.10^{\mathrm{b}}$ & $7.8 \pm 0.27^{c}$ & $6.7 \pm 0.23^{\mathrm{d}}$ & $4.3 \pm 0.15^{\mathrm{e}}$ & $11.4 \pm 0.39^{\mathrm{f}}$ \\
\hline S & $2.6 \pm 0.09^{\mathrm{a}}$ & $2.9 \pm 0.10^{\mathrm{b}}$ & $3.8 \pm 0.13^{c}$ & $3.6 \pm 0.12^{d}$ & $3.1 \pm 0.10^{\mathrm{b}}$ & $12 \pm 0.42^{\mathrm{e}}$ \\
\hline $\mathrm{Cu}$ & $0.2 \pm 0.007^{\mathrm{a}}$ & $1.3 \pm 0.04^{b}$ & $0.6 \pm 0.02^{c}$ & $0.6 \pm 0.02^{c}$ & $0.1 \pm 0.003^{\mathrm{d}}$ & $2.8 \pm 0.09^{\mathrm{e}}$ \\
\hline Co & $0.1 \pm 0.003^{\mathrm{a}}$ & n.d. & n.d. & $0.26 \pm 0.009^{b}$ & $0.2 \pm 0.007^{c}$ & $2.7 \pm 0.09^{d}$ \\
\hline $\mathrm{Zn}$ & $0.2 \pm 0.007^{\mathrm{a}}$ & $1.5 \pm 0.05^{\mathrm{b}}$ & $1.3 \pm 0.04^{c}$ & $0.76 \pm 0.02^{\mathrm{d}}$ & $0.45 \pm 0.01^{\mathrm{e}}$ & $2.3 \pm 0.08^{f}$ \\
\hline
\end{tabular}

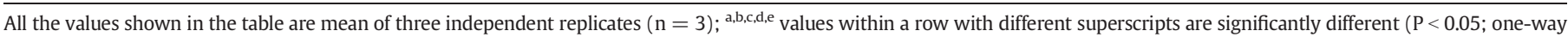
ANOVA).

Supplementary); the ash content in the biochar samples, for the holding time range of $30-120 \mathrm{~min}$, was only in the range of $9-22 \%$ compared to $39.5 \%$ in the MSS. The percentage values of major elements $(\mathrm{C}, \mathrm{H}$, and $\mathrm{N}$ ) in the biochar samples are provided in the Supplementary file. Metals composition in the biochar samples, obtained for different HTL holding time, were compared with raw MSS in Table 2. EDX analysis of the biochar samples and dried sewage sludge was also conducted to understand the elemental composition (see Supplementary). The concentrations of various metals in the biochar samples were lesser compared to their concentrations in the raw MSS as the metals got solubilized in the APL.

In the $\mathrm{AD}$ route, additional processes (e.g., destroying pathogens) might be required to recycle the nutrients from the digested sludge. Any living micro-organisms in the MSS would go through extreme heat and pressure during the HTL process, and hence, any potential pathogenic or other harmful organisms would not be able to survive. Thus, biochar could safely be applied in the field as a source of nutrients. In contrast to the HTL biochar and AD solid digestate, the pyrolysis biochar would have a much higher concentration of some metals as these get concentrated in the biochar (Gao et al., 2017). Biochar obtained from the pyrolysis of dry MSS could allow the higher percentage of phosphorus recovery by plants, although the recovery potential of nitrogen was very low due to its insoluble form in the biochar (Bridle and Pritchard, 2004). On the contrary, in both HTL and AD routes, the concentration of TN and TP in the solid byproduct would be low as fractions of these nutrients would also migrate to the liquid byproduct.

While the direct application of sewage sludge onto the field could have environmental and health effects due to the presence of toxic components, harmful microorganisms, biochar obtained from MSS still could be applied on the soil to enhance water and nutrient holding capacity of the soil. The carbon in the biochar could be environmentally persistent, and land application of biochar could simultaneously contribute to carbon sequestration (Lehmann, 2007). Biochar samples obtained from the HTL of different feedstock (e.g., macroalgae and microalgae biomass) had high surface area, porosity, and cation exchange sites and shown the promise as adsorbents of organic and inorganic compounds (Arun et al., 2018; Gwenzi et al., 2017; Zhou et al., 2018). Overall, HTL of MSS could offer the recovery of higher energy and the recycling of higher percentages of nutrients (i.e., both nitrogen and phosphorus) compared to conventional sludge management techniques (e.g., anaerobic digestion, pyrolysis).

\section{Conclusion}

This study demonstrated the feasibility of improved MSS management practices by recovering more than half of the energy by optimized HTL conditions while releasing the bulk of the nutrients from MSS to the APL and biochar, by-products of the HTL process, that could be used in specific microalgal cultivation and soil quality enhancement, respectively. Compared to other conventional techniques of energy recovery from MSS, optimized HTL conditions $\left(350{ }^{\circ} \mathrm{C}\right.$, and 45 min reaction time) could offer higher energy recovery (59\%) and energy return on investment (3.5) values. Increasing the HTL reaction time above $60 \mathrm{~min}$, reduced the biocrude yield, and subsequently reduced the ER and EROI values substantially. As the HTL reaction time increased, the release of TN in the APL was increasing while TP in the APL was decreasing. APL reduced the biomass density of Chlorella sp., possibly due to the presence of organic compounds that were toxic to Chlorella sp.; hence, Chlorella sp. couldn't efficiently recycle nutrients from the APL. The biomass yield of Picochlorum sp. in APL-added culture was higher than that of control culture as Picochlorum sp. was very efficient in utilizing APL nutrients and contributing to the removal of APL organics. The concentration of phosphorus in the biochar sample increased with an increase in HTL reaction time whereas the concentration of nitrogen remained in a similar range. Although there was a significant reduction of metal concentrations in the biochar samples, the long-term effects of land application of biochar on the soil quality need to be studied.

\section{Declaration of competing interest}

The authors declare that they have no known competing financial interests or personal relationships that could have appeared to influence the work reported in this paper.

\section{Acknowledgment}

The authors would like to acknowledge the support of Qatar National Research Fund (QNRF, a member of Qatar Foundation) for providing the funding (under grants UREP21-101-2-045, and NPRP8-646-2272) for this study. The authors thank Ms. Noora from Environmental Science Center (ESC), QU, for the GC-MS analysis of the biocrude samples. The authors would also like to acknowledge the support of Mr. Solaiman from Central laboratory Unit (CLU) of Qatar University for the ICP-OES analyses of the samples.

\section{Appendix A. Supplementary data}

Supplementary data to this article can be found online at https://doi. org/10.1016/j.scitotenv.2020.136775.

\section{References}

Alsheyab, M.A.T., Kusch-Brandt, S., 2018. Potential recovery assessment of the embodied resources in Qatar's wastewater. Sustainability 10 (9), 3055. https://doi.org/10.3390/ su10093055.

Arun, J., Varshini, P., Prithvinath, P.K., Priyadarshini, V., Gopinath, K.P., 2018. Enrichment of bio-oil after hydrothermal liquefaction (HTL) of microalgae C. vulgaris grown in wastewater: bio-char and post HTL wastewater utilization studies. Bioresour. Technol. 261, 182-187. https://doi.org/10.1016/j.biortech.2018.04.029.

Avelar, N.V., Ribeiro, B.C., Rezende, A.A.P., Silva, C.M., Carneiro, A. de C.O., Martins, M.A., 2019. Thermal drying of industrial sludge using forced aeration. Environ. Technol., 3297-3307 https://doi.org/10.1080/09593330.2018.1470679 (United Kingdom). 
Bridle, T.R., Pritchard, D., 2004. Energy and nutrient recovery from sewage sludge via pyrolysis. Water Sci. Technol. 50, 169-175. https://doi.org/10.2166/wst.2004.0562.

Castello, D., Pedersen, T.H., Rosendahl, L.A., 2018. Continuous hydrothermal liquefaction of biomass: a critical review. Energies 11 (11), 3165. https://doi.org/10.3390/ en11113165.

Chanaka Udayanga, W.D., Veksha, A., Giannis, A., Lim, T.-T., 2019. Pyrolysis derived char from municipal and industrial sludge: Impact of organic decomposition and inorganic accumulation on the fuel characteristics of char. Waste Management 83, 131-141. https://doi.org/10.1016/j.wasman.2018.11.008.

Correa-Reyes, G., Viana, M.T., Marquez-Rocha, F.J., Licea, A.F., Ponce, E., Vazquez-Duhalt, R., 2007. Nonylphenol algal bioaccumulation and its effect through the trophic chain. Chemosphere 68, 662-670. https://doi.org/10.1016/j.chemosphere.2007.02.030.

Das, P., AbdulQuadir, M., Thaher, M., Khan, S., Chaudhary, A.K., Alghasal, G., Al-Jabri, H.M.S.J., 2018a. Microalgal bioremediation of petroleum-derived low salinity and low pH produced water. J. Appl. Phycol. 31, 435-444. https://doi.org/10.1007/ s10811-018-1571-6.

Das, P., AbdulQuadir, M., Thaher, M.I., Alghasal, G.S.H.S., Aljabri, H.M.S.J., 2018b. Microalgal nutrients recycling from the primary effluent of municipal wastewater and use of the produced biomass as bio-fertilizer. Int. J. Environ. Sci. Technol. 16 3355-3364. https://doi.org/10.1007/s13762-018-1867-8.

Das, P., Khan, S., Thaher, M., AbdulQuadir, M., Hoekman, S.K., Al-Jabri, H., 2019a. Effect of harvesting methods on the energy requirement of Tetraselmis sp. biomass production and biocrude yield and quality. Bioresour. Technol. 284, 9-15. https://doi.org/ 10.1016/j.biortech.2019.03.118.

Das, P., Thaher, M.I., Khan, S., AbdulQuadir, M., Chaudhary, A.K., Alghasal, G., Al-Jabri, H., 2019b. Comparison of biocrude oil production from self-settling and non-settling microalgae biomass produced in the Qatari desert environment. Int. J. Environ. Sci. Technol. 16, 7443-7454. https://doi.org/10.1007/s13762-019-02364-w.

Das, P., AbdulQuadir, M., Thaher, M., Khan, S., Chaudhary, A.K., Al-Jabri, H., 2020. A feasibility study of utilizing hydrothermal liquefaction derived aqueous phase as nutrients for semi-continuous cultivation of Tetraselmis sp. Bioresour. Technol. 295, 122310. https://doi.org/10.1016/j.biortech.2019.122310.

Delgadillo-Mirquez, L., Lopes, F., Taidi, B., Pareau, D., 2016. Nitrogen and phosphate removal from wastewater with a mixed microalgae and bacteria culture. Biotechnol. Rep. 11, 18-26. https://doi.org/10.1016/j.btre.2016.04.003.

Foley, P.M., Beach, E.S., Zimmerman, J.B., 2011. Algae as a source of renewable chemicals: opportunities and challenges. Green Chem. 13, 1399-1405. https://doi.org/10.1039/ C1GC00015B.

Gao, N., Quan, C., Liu, B., Li, Z., Wu, C., Li, A., 2017. Continuous pyrolysis of sewage sludge in a screw-feeding reactor: products characterization and ecological risk assessment of heavy metals. Energy Fuel 31 (5), 5063-5072. https://doi.org/10.1021/acs. energyfuels.6b03112.

Gray, Donald, M.D., 2008. Anaerobic Digestion of Food Waste. Final Report. U.S. Environ. Prot. Agency Reg, p. 9.

Gwenzi, W., Chaukura, N., Noubactep, C., Mukome, F.N.D., 2017. Biochar-based water treatment systems as a potential low-cost and sustainable technology for clean water provision. J. Environ. Manag. 197, 732-749. https://doi.org/10.1016/j. jenvman.2017.03.087.

Han, Y., Hoekman, S.K., Cui, Z., Jena, U., Das, P., 2019. Hydrothermal liquefaction of marine microalgae biomass using co-solvents. Algal Res. 38, 101421. https://doi.org/ 10.1016/j.algal.2019.101421.

Jain, A., Balasubramanian, R., Srinivasan, M.P., 2016. Hydrothermal conversion of biomass waste to activated carbon with high porosity: a review. Chem. Eng. J. 283, 789-805. https://doi.org/10.1016/j.cej.2015.08.014.

Karaca, C., Sözen, S., Orhon, D., Okutan, H., 2018. High temperature pyrolysis of sewage sludge as a sustainable process for energy recovery. Waste Manag. 78, 217-226. https://doi.org/10.1016/j.wasman.2018.05.034.

Kaur, G., Luo, L., Chen, G., Wong, J.W.C., 2019. Integrated food waste and sewage treatment - a better approach than conventional food waste-sludge co-digestion for higher energy recovery via anaerobic digestion. Bioresour. Technol. 289, 121698. https://doi.org/10.1016/j.biortech.2019.121698.

Kleemann, R., Chenoweth, J., Clift, R., Morse, S., Pearce, P., Saroj, D., 2017. Comparison of phosphorus recovery from incinerated sewage sludge ash (ISSA) and pyrolysed sewage sludge char (PSSC). Waste Manag. 60, 201-210. https://doi.org/10.1016/j. wasman.2016.10.055.

Korzeniewska, E., Harnisz, M., 2018. Relationship between modification of activated sludge wastewater treatment and changes in antibiotic resistance of bacteria. Sci. Total Environ. 639, 304-315. https://doi.org/10.1016/j.scitotenv.2018.05.165.

Lehmann, J., 2007. Bio-energy in the black. Front. Ecol. Environ. 5, 381-387. https://doi. org/10.1890/1540-9295(2007)5[381:BITB]2.0.CO;2.

Leng, L., Yuan, X., Huang, H., Jiang, H., Chen, X., Zeng, G., 2014. The migration and transformation behavior of heavy metals during the liquefaction process of sewage sludge. Bioresour. Technol. 167, 144-150. https://doi.org/10.1016/j.biortech.2014.05.119.
Leng, L., Li, J., Wen, Z., Zhou, W., 2018. Use of microalgae to recycle nutrients in aqueous phase derived from hydrothermal liquefaction process. Bioresour. Technol. 256, 529-542. https://doi.org/10.1016/j.biortech.2018.01.121.

Lim, J.-H., Cha, J.-S., Kong, B.-J., Baek, S.-H., 2018. Characterization of odorous gases at landfill site and in surrounding areas. J. Environ. Manag. 206, 291-303. https://doi. org/10.1016/j.jenvman.2017.10.045.

Liu, R., Tian, W., Kong, S., Meng, Y., Wang, H., Zhang, J., 2018. Effects of inorganic and organic acid pretreatments on the hydrothermal liquefaction of municipal secondary sludge. Energy Convers. Manag. 174, 661-667. https://doi.org/10.1016/j. enconman.2018.08.058.

Loftus, S.E., Johnson, Z.I., 2019. Reused cultivation water accumulates dissolved organic carbon and uniquely influences different marine microalgae. Front. Bioeng. Biotechnol. 7, 101. https://doi.org/10.3389/fbioe.2019.00101.

López-Pacheco, I.Y., Carrillo-Nieves, D., Salinas-Salazar, C., Silva-Núñez, A., ArévaloGallegos, A., Barceló, D., Afewerki, S., Iqbal, H.M.N., Parra-Saldívar, R., 2019a. Combination of nejayote and swine wastewater as a medium for Arthrospira maxima and Chlorella vulgaris production and wastewater treatment. Sci. Total Environ. 676, 356-367. https://doi.org/10.1016/j.scitotenv.2019.04.278.

López-Pacheco, I.Y., Salinas-Salazar, C., Silva-Núñez, A., Rodas-Zuluaga, L.I., DonosoQuezada, J., Ayala-Mar, S., Barceló, D., Iqbal, H.M.N., Parra-Saldívar, R., 2019b. Removal and biotransformation of 4-nonylphenol by Arthrospira maxima and $P$ vulgaris consortium. Environ. Res. 179, 108848. https://doi.org/10.1016/j. envres.2019.108848.

Lu, J., Watson, J., Zeng, J., Li, H., Zhu, Z., Wang, M., Zhang, Y., Liu, Z., 2018. Biocrude production and heavy metal migration during hydrothermal liquefaction of swine manure. Process. Saf. Environ. Prot. 115, 108-115. https://doi.org/10.1016/j. psep.2017.11.001.

Maag, A.R., Paulsen, A.D., Amundsen, T.J., Yelvington, P.E., Tompsett, G.A., Timko, M.T., 2018. Catalytic hydrothermal liquefaction of food waste using cezrox. Energies 11 , 564. https://doi.org/10.3390/en11030564.

Malins, K., Kampars, V., Brinks, J., Neibolte, I., Murnieks, R., Kampare, R., 2015. Bio-oil from thermo-chemical hydro-liquefaction of wet sewage sludge. Bioresour. Technol. 187, 23-29. https://doi.org/10.1016/J.BIORTECH.2015.03.093.

Mu, L., Zhang, L., Zhu, K., Ma, J., Ifran, M., Li, A., 2019. Anaerobic co-digestion of sewage sludge, food waste and yard waste: synergistic enhancement on process stability and biogas production. Sci. Total Environ., 135429 https://doi.org/10.1016/j. scitotenv.2019.135429.

Muñoz, R., Guieysse, B., 2006. Algal-bacterial processes for the treatment of hazardous contaminants: a review. Water Res. 40, 2799-2815. https://doi.org/10.1016/j. watres.2006.06.011.

Park, H.J., Heo, H.S., Park, Y.K., Yim, J.H., Jeon, J.K., Park, J., Ryu, C., Kim, S.S., 2010. Clean bio-oil production from fast pyrolysis of sewage sludge: effects of reaction conditions and metal oxide catalysts. Bioresour. Technol. 101, S83-S85. https://doi.org/10.1016/ j.biortech.2009.06.103.

Peterson, A.A., Vogel, F., Lachance, R.P., Fröling, M., Antal Jr., M.J., Tester, J.W., 2008. Thermochemical biofuel production in hydrothermal media: a review of sub- and supercritical water technologies. Energy Environ. Sci. 1, 32. https://doi.org/10.1039/ b810100k.

Prestigiacomo, C., Costa, P., Pinto, F., Schiavo, B., Siragusa, A., Scialdone, O., Galia, A., 2019. Sewage sludge as cheap alternative to microalgae as feedstock of catalytic hydrothermal liquefaction processes. J. Supercrit. Fluids 143, 251-258. https://doi.org/10.1016/ j.supflu.2018.08.019.

Qatar Ministry of Development Planning and Statistics, 2017. Water Statistics in the State of Qatar 2015. Qatar Ministry of Development Planning and Statistics, Doha, Qatar.

Qian, T.-T., Jiang, H., 2014. Migration of phosphorus in sewage sludge during different thermal treatment processes. ACS Sustain. Chem. Eng. 2, 1411-1419. https://doi. org/10.1021/sc400476j.

Qian, L., Wang, S., Savage, P.E., 2017. Hydrothermal liquefaction of sewage sludge under isothermal and fast conditions. Bioresour. Technol. 232, 27-34. https://doi.org/ 10.1016/j.biortech.2017.02.017.

Qian, L., Wang, S., Savage, P.E., 2020. Fast and isothermal hydrothermal liquefaction of sludge at different severities: reaction products, pathways, and kinetics. Appl. Energy 260, 114312. https://doi.org/10.1016/j.apenergy.2019.114312.

Suárez-Iglesias, O., Urrea, J.L., Oulego, P., Collado, S., Díaz, M., 2017. Valuable compounds from sewage sludge by thermal hydrolysis and wet oxidation. A review. Sci. Total Environ. 584-585, 921-934. https://doi.org/10.1016/j.scitotenv.2017.01.140.

Tomei, M.C., Bertanza, G., Canato, M., Heimersson, S., Laera, G., Svanström, M., 2016. Techno-economic and environmental assessment of upgrading alternatives for sludge stabilization in municipal wastewater treatment plants. J. Clean. Prod. 112, 3106-3115. https://doi.org/10.1016/j.jclepro.2015.10.017.

Torri, C., Fabbri, D., 2014. Biochar enables anaerobic digestion of aqueous phase from intermediate pyrolysis of biomass. Bioresour. Technol. 172, 335-341. https://doi.org/ 10.1016/j.biortech.2014.09.021. 
Trinh, T.N., Jensen, P.A., Kim, D.J., Knudsen, N.O., Sørensen, H.R., 2013. Influence of the pyrolysis temperature on sewage sludge product distribution, bio-oil, and char properties. Energy Fuel 27, 1419-1427. https://doi.org/10.1021/ef301944r.

Valdez, P.J., Tocco, V.J., Savage, P.E., 2014. A general kinetic model for the hydrothermal liquefaction of microalgae. Bioresour. Technol. 163, 123-127. https://doi.org/ 10.1016/j.biortech.2014.04.013.

Wang, Q., Wei, W., Gong, Y., Yu, Q., Li, Q., Sun, J., Yuan, Z., 2017. Technologies for reducing sludge production in wastewater treatment plants: state of the art. Sci. Total Environ. 587-588, 510-521. https://doi.org/10.1016/j.scitotenv.2017.02.203.

Wang, W., Yu, Q., Meng, H., Han, W., Li, J., Zhang, J., 2018. Catalytic liquefaction of municipal sewage sludge over transition metal catalysts in ethanol-water co-solvent Bioresour. Technol. 249, 361-367. https://doi.org/10.1016/j.biortech.2017.09.205.

Wang, S., Yu, S., Lu, Q., Liao, Y., Li, H., Sun, L., Wang, H., Zhang, Y., 2019. Development of an alkaline/acid pre-treatment and anaerobic digestion (APAD) process for methane generation from waste activated sludge. Sci. Total Environ., 134564 https://doi.org/ 10.1016/j.scitotenv.2019.134564.

Watson, J., Si, B., Li, H., Liu, Z., Zhang, Y., 2017. Influence of catalysts on hydrogen production from wastewater generated from the HTL of human feces via catalytic hydrothermal gasification. Int. J. Hydrog. Energy 42, 20503-20511. https://doi.org/ 10.1016/j.ijhydene.2017.05.083.

Werle, S., Sobek, S., 2019. Gasification of sewage sludge within a circular economy perspective: a Polish case study. Environ. Sci. Pollut. Res., 1-11 https://doi.org/10.1007/ s11356-019-05897-2.
Xia, A., Murphy, J.D., 2016. Microalgal cultivation in treating liquid digestate from biogas systems. Trends Biotechnol. 34, 264-275. https://doi.org/10.1016/j. tibtech.2015.12.010

Xu, Y., Dai, X., 2020. Integrating multi-state and multi-phase treatment for anaerobic sludge digestion to enhance recovery of bio-energy. Sci. Total Environ. 698, 134196. https://doi.org/10.1016/j.scitotenv.2019.134196.

Xu, D., Lin, G., Liu, L., Wang, Y., Jing, Z., Wang, S., 2018. Comprehensive evaluation on product characteristics of fast hydrothermal liquefaction of sewage sludge at different temperatures. Energy 159, 686-695. https://doi.org/10.1016/j.energy.2018.06.191.

Yang, X., Nie, J., Wang, D., Zhao, Z., Kobayashi, M., Adachi, Y., Shimizu, K., Lei, Z., Zhang, Z., 2019. Enhanced hydrolysis of waste activated sludge for methane production via anaerobic digestion under N2-nanobubble water addition. Sci. Total Environ. 693, 133524. https://doi.org/10.1016/j.scitotenv.2019.07.330.

Yoo, G., Park, M.S., Yang J.-W., Choi, M., 2015. Lipid content in microalgae determines the quality of biocrude and Energy Return On Investment of hydrothermal liquefaction. Appl. Energy 156, 354-361. https://doi.org/10.1016/j.apenergy.2015.07.020.

Zhao, G., Garrido-Baserba, M., Reifsnyder, S., Xu, J.C., Rosso, D., 2019. Comparative energy and carbon footprint analysis of biosolids management strategies in water resource recovery facilities. Sci. Total Environ. 665, 762-773. https://doi.org/10.1016/j. scitotenv.2019.02.024

Zhou, Y., Zhang, H., Cai, L., Guo, J., Wang, Y., Ji, L., Song, W., 2018. Preparation and characterization of macroalgae biochar nanomaterials with highly efficient adsorption and photodegradation ability. Materials 11, 1709 (Basel). 